\title{
DESENVOLVIMENTO DE ALTERNARIA SOLANI EM DIFERENTES MEIOS DE CULTURA, FOTOPERÍODO E TEMPERATURA
}

\author{
Camila Hendges, Márcia de Holanda Nozaki
}

Pontifícia Universidade Católica do Paraná - PUC, Departamento de Agronomia. E-mail: hendgescamila@hotmail.com

\begin{abstract}
RESUMO
O tomateiro está entre as hortaliças mais cultivadas, porém é altamente susceptível ao ataque de patógenos. A pinta-preta é uma das doenças mais frequentes sendo constatada em condições de alta umidade e temperatura, ou seja, ideais ao desenvolvimento do patógeno. $O$ objetivo do presente trabalho foi avaliar o efeito dos meios de cultura, temperatura e fotoperíodo no crescimento micelial e esporulação de Alternaria solani. Foram realizados diferentes ensaios. O primeiro, de diferentes meios de cultura com os tratamentos: 1) BDA; 2) BDA+Polpa de Tomate; 3) BDA+Folha de Tomate; 4) BDA+Cenoura e 5) Aveia+Ágar, com 4 repetições. O segundo de luminosidade: 1) escuro, 2) fotoperíodo alternado e 3) claro contínuo, com 7 repetições. E, por fim, o de temperatura, constituído por: 1) $25^{\circ} \mathrm{C}$; 2) temperatura ambiente e 3) $30{ }^{\circ} \mathrm{C}$, com 7 repetições. Foram realizadas avaliações diárias de crescimento micelial e esporulação do patógeno ao final de cada ensaio. Dados foram submetidos à análise pelo teste de Tukey a 5\%. O meio de cultura contendo BDA+polpa de tomate apres entou o melhor crescimento micelial e esporulação da Alternaria solani, apresentando-se como mais adequado para seu isolamento. A luminosidade interferiu significativamente na esporulação do fungo, sendo o fotoperíodo escuro o que apresentou a maior esporulação, não havendo diferença para crescimento micelial. A temperatura de $30^{\circ} \mathrm{C}$ proporcionou o melhor tratamento para isolamento do patógeno, tanto em crescimento micelial, quanto em esporulação.
\end{abstract}

Palavras-Chave: etiologia; Lycopersicon esculentum; pinta preta.

\section{ALTERNARIA SOLANI DEVELOPMENT IN DIFERENT CULTURE MEDIA, PHOTOPERIOD AND TEMPERATURE}

\begin{abstract}
Tomato is among the most cultivated vegetables, but is highly susceptible to attack of pathogens. The blight is one of the most frequent diseases and is observed in high humidity and temperature, ideal environmental conditions for the development of the pathogen. The objective of this study was to evaluate the effect of culture media, temperature and photoperiod on Alternaria solani mycelia growth and sporulation. Different assays were performed. The first, of different culture media with the treatments: 1 ) PDA; 2) PDA+Tomato pulp; 3) PDA+Tomato Leaf; 4) PDA+Carrot and 5) Oatmeal+Agar with 4 replications. The second of light influence: 1) dark, 2) alternating photoperiod and 3) continuous light, with 7 repetitions. And, temperature, constituted by: 1) $25{ }^{\circ} \mathrm{C}$; 2) $30{ }^{\circ} \mathrm{C}$ and 3) ambient temperature with 7 replicates. Daily reviews of mycelia growth and sporulation of the pathogen were performed. Data were analyzed by Tukey test at $5 \%$. All variables showed interference on growth and sporulation of Alternaria solani, highlighting the PDA culture medium + Tomato Pulp, dark photoperiod and $30{ }^{\circ} \mathrm{C}$. It can be concluded that in studies of the of pathogen etiology, climatic and environmental factors may influence their growth and reproduction.
\end{abstract}

Keywords: etiology; Lycopersicon esculentum; black spot.

\section{INTRODUÇÃO}

O tomateiro está entre as hortaliças mais cultivadas, sendo o Brasil considerado um dos maiores produtores mundiais e o maior da
América Latina (FILGUEIRA, 2003). Em contrapartida, a cultura é susceptível ao ataque de diversos patógenos, tanto de solo, raiz e parte aérea. 
As doenças fúngicas são as mais encontradas no cultivo geral, sendo superior às bacterioses e viroses. Com isso, a tomaticultura é a atividade agrícola que mais utiliza fungicida (FILGUEIRA, 2003).

A pinta-preta do tomateiro, cujo agente causal é o fungo Alternaria solani, é uma das doenças mais frequentes e ocorre em todas regiões de cultivo. Esta doença provoca prejuízos diretos na produtividade, por infectar os frutos e também, prejuízos indiretos, reduzindo o vigor da planta e danificando os frutos, pois causa desfolha e os frutos ficam mais expostos ao sol (VALE et al., 2004).

A intensidade da doença depende de alguns fatores, como a época em que a doença se estabelece na cultura, a taxa de progresso da doença, a cultivar utilizada e também as condições ambientais, podendo ser favoráveis ou não (VALE et al., 2004).

A maior incidência da pinta preta é constatada em condições de alta umidade e temperatura, ou seja, nas condições ambientais ideais ao desenvolvimento do patógeno. $\mathrm{O}$ uso de variedades resistentes é considerado o método ideal de controle de doenças, no entanto as variedades comerciais de tomate recomendadas para o plantio no Brasil são suscetíveis à doença (DILL, 2009).

Os sintomas aparecem inicialmente nas folhas velhas, localizadas no baixeiro e posteriormente, progridem para as partes mais altas da planta. Quando as condições ambientais são favoráveis o patógeno incide em folhas mais novas. As lesões necróticas têm coloração marrom-escura a preta, com bordas bem definidas, podendo ser mais ou menos circulares e apresentam um halo amarelado. No caule e pecíolos de plantas adultas as lesões são escuras, alongadas e circulares. Nos frutos o fungo causa lesões escuras, deprimidas e com presença típica de anéis concêntricos (PEREIRA et al., 2013).

Estudos têm comprovado que os métodos clássicos de controle de patógenos acabam sendo prejudiciais, uma vez que, os fungicidas sintéticos são mais persistentes no ambiente e menos seletivos, provocando alterações na biodiversidade do local, assim essa problemática vem reforçando a necessidade de pesquisas em busca de métodos alternativos para o controle de fitopatógenos (CAMARGO, 2007).

Muitos trabalhos vêm sendo realizados comprovando a ação fungitóxica dos óleos e extratos de plantas medicinais, inibindo $o$ crescimento micelial e produção de esporos de patógenos, confirmando sua eficácia, tanto em pulverizações objetivando o controle de doenças em partes aéreas, como no tratamento de solo e de sementes (DILL, 2009). É nesse contexto que o uso de óleos essenciais, a utilização de produtos de fontes naturais, como plantas, podem substituir o uso dos agroquímicos e sanar o impacto sobre os seres vivos e o meio ambiente.

O presente trabalho teve como objetivo verificar a influência do meio de cultura, da temperatura e do fotoperíodo no crescimento micelial e esporulação de Alternaria solani.

\section{MATERIAL E MÉTODOS}

$O$ experimento foi conduzido no Laboratório de Fitopatologia da Pontifícia Universidade Católica do Paraná, em Toledo (PR), durante os anos de 2013 e 2014.

Para obtenção do isolado de Alternaria solani, agente causal da pinta preta, foram utilizadas folhas sintomáticas provenientes da plantação local de tomates, cv. Santamélia, coletados no município de Toledo (PR). Destas, foram retirados pequenos fragmentos de tecido doente, com auxílio de bisturi. Após isto, as frações de tecidos foram submetidas à assepsia, em que foram mergulhadas em solução de hipoclorito de sódio (3:1), por 1 minuto, posteriormente lavadas em água corrente, objetivando a remoção de fungos secundários. Em seguida, os fragmentos foram depositados em placas de Petri contendo meio de cultura BDA (batata-dextrose-ágar) para o desenvolvimento e crescimento da colônia (ALFENAS; MAFIA, 2007).

Os óleos essenciais utilizados no experimento de controle do patógeno foram obtidos na Farmácia de Manipulação Natural Farma, na cidade de Toledo (PR), com $100 \%$ de pureza das amostras.

\section{INFLUÊNCIA DE DIFERENTES MEIOS DE CULTURA NO CRESCIMENTO MICELIAL E ESPORULAÇÃO DE Alternaria solani}

Para avaliar a influência de diferentes meios de cultura no crescimento micelial e esporulação do patógeno, adotou-se o delineamento experimental inteiramente casualizado, com cinco tratamentos e cinco repetições, sendo que cada repetição foi composta por uma placa de Petri.

Os tratamentos foram: BDA (100g de batata, $10 \mathrm{~g}$ de dextrose e $10 \mathrm{~g}$ de ágar), $\mathrm{BDA}+$ folhas de tomate $(100 \mathrm{~g}$ de batata, $10 \mathrm{~g}$ de 
dextrose, $10 \mathrm{~g}$ de ágar e $100 \mathrm{~g}$ de folhas sadias de tomate trituradas), BDA+polpa de tomate $(100 \mathrm{~g}$ de batata, $10 \mathrm{~g}$ de dextrose, $10 \mathrm{~g}$ de ágar e $100 \mathrm{~g}$ de polpa de tomate batida), BDA+cenoura (100g de batata, $10 \mathrm{~g}$ de dextrose, $10 \mathrm{~g}$ de ágar e $100 \mathrm{~g}$ de cenoura triturada) e Aveia+ágar (100g de aveia em flocos, $10 \mathrm{~g}$ de dextrose, $10 \mathrm{~g}$ de ágar), concentrações estas para $1 \mathrm{~L}$ de meio de cultura, adaptado de Alfenas e Mafia (2007). Os meios de cultura foram autoclavados $\left(121{ }^{\circ} \mathrm{C} / 20 \mathrm{~min}\right) \mathrm{e}$ transferidos para placas de Petri de $7 \mathrm{~cm}$ de diâmetro.

Após a solidificação do meio de cultura nas placas de Petri, foram depositados no centro de cada placa, discos miceliais de $9 \mathrm{~mm}$ da colônia pura do fungo, com 22 dias de idade.

As placas foram vedadas e mantidas em temperatura ambiente e fotoperíodo alternado (12 horas luz/12 horas escuro).

A avaliação do crescimento micelial (mm/dia) baseou-se na determinação da velocidade de crescimento, através de medições do diâmetro das colônias, em dois eixos perpendiculares entre si, até que a colônia de algum dos isolados atingisse completamente as bordas da placa de Petri (STANGARLIN et al., 1999). A medição foi realizada com auxílio de paquímetro digital.

A contagem dos esporos foi realizada ao término da avaliação de crescimento micelial. Nesta ocasião, adicionou-se $10 \mathrm{~mL}$ de água deionizada em cada placa de cada tratamento. Com auxílio de um lâmina de vidro, foi efetuada a raspagem superficial da colônia, facilitando o desprendimento dos esporos do micélio. Posteriormente, a suspensão foi filtrada com auxílio de gaze em um copo de béquer de $50 \mathrm{~mL}$. Em seguida, foi coletado $1 \mathrm{~mL}$ da solução que foi depositada sobre a câmara de Neubauer para contagem do número de esporos.

\section{INFLUÊNCIA DA LUMINOSIDADE NO}

\section{CRESCIMENTO MICELIAL E ESPORULAÇÃO DE}

Alternaria solani

Dando continuidade aos ensaios, após a seleção do melhor meio de cultura, este foi selecionado para o respectivo ensaio.

O delineamento experimental adotado foi inteiramente casualizado, com três tratamentos e sete repetições. Os tratamentos foram: 0, 50 e $100 \%$ de luz. Cada placa constituiu uma repetição.

O meio de cultura utilizado foi BDA+polpa de tomate, o qual apresentou melhor resultado em ensaio prévio, preparado com $100 \mathrm{~g}$ de batata, $10 \mathrm{~g}$ de dextrose, $10 \mathrm{~g}$ de ágar e $100 \mathrm{~g}$ de polpa de tomate batida, concentração esta para $1 \mathrm{~L}$ de meio de cultura. $O$ meio foi autoclavado $\left(121^{\circ} \mathrm{C} / 20 \mathrm{~min}\right.$ ) e transferido para placas de Petri de $7 \mathrm{~cm}$ de diâmetro.

Após a solidificação do meio de cultura, discos de $9 \mathrm{~mm}$ de diâmetro do patógeno, com 22 dias de idade, foram transferidos para placas de Petri, sendo estas vedadas e mantidas sob os diferentes regimes de luz (tratamentos) e temperatura ambiente.

As placas do tratamento com $0 \%$ de luz foram envoltas por papel alumínio, aquelas com $50 \%$ de luz foram armazenadas em um fotoperíodo de 12 horas luz/12 horas escuro e as placas com $100 \%$ de luz permaneceram com luminosidade constante durante toda a condução do experimento.

As avaliações consistiram de medidas do crescimento do micélio diariamente até sétimo dia (quando a colônia de um dos isolados atingiu a margem da placa de Petri) e contagem de esporos conforme experimento anterior.

\section{INFLUÊNCIA DA TEMPERATURA NO CRESCIMENTO MICELIAL E ESPORULAÇÃO DE Alternaria solani}

Com os dados dos experimentos prévios em mãos, foi realizado novo ensaio para avaliar a influência da temperatura no crescimento micelial e esporulação do fungo. Para tanto, utilizou-se meio de cultura e luminosidade que apresentaram resultados mais expressivos em experimentos prévios.

0 delineamento experimental foi inteiramente casualizado, com três tratamentos e sete repetições. Cada placa constituindo uma repetição. Os tratamentos utilizados foram: 20 ${ }^{\circ} \mathrm{C}$, temperatura ambiente $\left( \pm 25^{\circ} \mathrm{C}\right)$ e $30^{\circ} \mathrm{C}$.

$O$ meio de cultura empregado foi BDA+polpa de tomate, sendo preparado com $100 \mathrm{~g}$ de batata, $10 \mathrm{~g}$ de dextrose, $10 \mathrm{~g}$ de ágar e $100 \mathrm{~g}$ de polpa de tomate batida, para concentração de $1 \mathrm{~L}$ de meio de cultura. $\mathrm{O}$ meio foi autoclavado $\left(121^{\circ} \mathrm{C} / 20 \mathrm{~min}\right)$ e transferido para placas de Petri de $7 \mathrm{~cm}$ de diâmetro.

No centro de cada placa de Petri foram depositados discos com $9 \mathrm{~mm}$ de diâmetro do isolado de Alternaria solani, com 20 dias de cultivo. As placas foram vedadas e posteriormente submetidas aos diferentes tratamentos (temperaturas) com fotoperíodo escuro, o qual apresentou melhores respostas em 
ensaio prévio. Para simular o tratamento de escuro contínuo, as placas dos tratamentos foram envoltas por papel alumínio antes de seu armazenamento.

Diariamente o diâmetro da colônia foi medido com auxílio de um paquímetro digital, avaliando nos sentidos diametricamente opostos do desenvolvimento da colônia do fungo, até o momento em que uma das placas, em algum dos tratamentos, atingisse a borda da placa de Petri.

A contagem de esporos foi realizada ao término da medição do crescimento micelial, com auxílio de uma câmara de Neubauer, conforme relatado anteriormente.
Os dados obtidos foram submetidos à análise estatística utilizando a comparação de médias através do teste de Tukey a 5\% de probabilidade, através do programa estatística SASM-Agri (CANTERI et al., 2001).

\section{RESULTADOS E DISCUSSÃO}

INFLUÊNCIA DE DIFERENTES MEIOS DE CULTURAS NO CRESCIMENTO MICELIAL E ESPORULAÇÃO DE Alternaria solani

A avaliação do crescimento micelial finalizou ao sétimo dia após a instalação do experimento, quando a colônia presente no tratamento de BDA+polpa de tomate atingiu inteiramente a borda da placa de Petri (Figura 1).

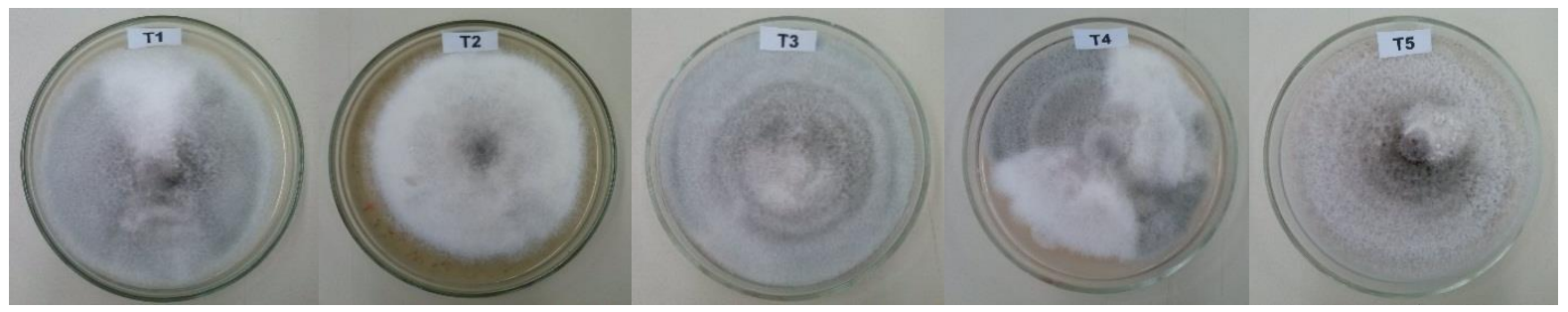

Figura 1. Detalhe de placas com colônias de Alternaria solani submetido aos diferentes meios de cultura, sendo T1 (BDA); T2 (BDA+folha); T3 (BDA+polpa); T4 (BDA+cenoura) e T5 (aveia+ágar). Fonte: a autora, 2014.

O crescimento micelial de Alternaria solani foi influenciado pelo meio de cultura, conforme Tabela 1. O meio BDA+polpa se destacou dos demais, entretanto apresentou resultados semelhantes aos meios de BDA e Aveia ágar. Enquanto que, os meios de BDA+folha e BDA+cenoura, apresentaram menor crescimento micelial.

A maior concentração de açúcar no meio de cultura BDA+polpa de tomate influenciou no aumento da produção de esporos e crescimento micelial.

Tabela 1. Influência de diferentes meios de cultura sobre o crescimento micelial (mm) e esporulação $\left(\times 10^{4} / \mathrm{mL}\right)$ de Alternaria solani aos 07 dias de incubação. Toledo, 2014.

\begin{tabular}{ccc}
\hline MEIOS DE CULTURAS & CRESCIMENTO MICELIAL & ESPOROS \\
\hline BDA & $78,233 \mathrm{ab}$ & $0,937 \mathrm{c}$ \\
BDA+FOLHA & $75,583 \mathrm{~b}$ & $1,265 \mathrm{~b}$ \\
BDA+POLPA & $87,586 \mathrm{a}$ & $1,906 \mathrm{a}$ \\
BDA+CENOURA & $75,926 \mathrm{~b}$ & $0,531 \mathrm{~d}$ \\
AVEIA+AGAR & $79,831 \mathrm{ab}$ & $0,984 \mathrm{bc}$ \\
\hline MÉDIA & 79,432 & 1,125 \\
CV (\%) & 6,35 & 11,96
\end{tabular}

Nota: Médias seguidas da mesma letra na coluna não diferem significativamente entre si pelo teste de Tukey, a $5 \%$ de probabilidade. 
Resultados semelhantes foram observados por Pulz e Massola (2009), que também verificaram a influência significativa dos meios de culturas no crescimento micelial de Alternaria dauci e $A$. solani onde o meio V8-ágar apresentou-se superior ao meio de Aveia e BDA. Os autores também verificaram que o meio de cultura contendo Aveia proporcionou desenvolvimento similar ao observado em V8ágar, semelhante ao presente trabalho.

Silva e Melo (1997) também apresentaram resultados semelhantes quando avaliaram o crescimento micelial e esporulação de Alternaria alternata em que o meio de cultura contendo suco V8 foi superior ao meio Aveia-ágar e BDA.

Isenberg e Nozaki (2009) avaliando cinco meios de culturas para crescimento de Diplocarpon rosae (pinta preta da roseira), observaram que o meio contendo folhas de roseira apresentou o maior crescimento micelial da colônia fúngicas, contradizendo os resultados do presente trabalho, em que o meio contendo folhas da planta testada apresentou o menor crescimento micelial. Este fato pode ser explicado pela presença de nutrientes nas folhas e na polpa de tomate, que favorecem o desenvolvimento do patógeno.

Segundo Dhingra e Sinclair (1995) apud Rodrigues (2005), meios de cultura contendo na sua composição extratos de folhas, frutos ou partes de planta podem suprimir a necessidade nutricional de patógenos para esporular em meios de culturas, estimulando o crescimento micelial e esporulação de vários fungos.

A eficiência do meio de cultura V8 também foi verificada por Colturato (2006) quando realizou o isolamento de Alternaria alternata em diferentes meios de cultura.
Com relação a contagem de esporos de Alternaria solani nas diferentes composições de meios de cultura, observa-se que 0 meio contendo BDA+polpa apresentou diferença significativa dos demais meios testados, enquanto que o meio de BDA+cenoura foi o que apresentou menor esporulação (Tabela 1).

Queiroz et al. (2004), constataram a presença de esporos em meios contendo V8, assemelhando-se ao presente trabalho, em que $o$ tratamento com polpa de tomate diferenciou-se significativamente em quantidade de esporos dos demais meios testados. Meio este considerado favorável para reprodução de Alternaria solani.

A importância da presença de suco de tomate para produção de esporos de Alternaria também foi verificada Silva e Melo (1997), ao observarem que o meio de cultura V8 apresentou quantidade significativa de esporos.

Resultados semelhantes também foram apresentados por Nozaki et al. (2004), no qual o meio de cultura Aveia-ágar foi superior ao meio BDA referente ao crescimento micelial e produção de picnídios de Diaporthe citri (melanose dos citros).

\section{INFLUÊNCIA DA LUMINOSIDADE NO CRECIMENTO MICELIAL E ESPORULAÇÃO Alternaria solani}

$O$ crescimento micelial não foi influenciado pela luminosidade, porém a esporulação sofreu interferência significativa. A condição escura apresentou maior esporulação do patógeno, seguido dos tratamentos com luz alternada e luz contínua, que não diferenciaramse entre si, conforme pode ser observado na Tabela 2.

Ao sétimo dia, a colônia submetida à $100 \%$ de luz atingiu a borda da placa de Petri. O regime luminoso não influenciou sobre o crescimento micelial do patógeno (Figura 2).

Tabela 2. Influência do fotoperíodo sobre o crescimento micelial $(\mathrm{mm})$ e esporulação $\left(\times 10^{4} / \mathrm{mL}\right)$ de Alternaria solani, aos 07 dias de incubação. Toledo, 2014.

\begin{tabular}{ccc}
\hline FOTOPERÍODO & CRESCIMENTO MICELIAL & ESPOROS \\
\hline 0\% LUZ & $84,759 \mathrm{a}$ & $3,640 \mathrm{a}$ \\
$50 \%$ LUZ & $84,776 \mathrm{a}$ & $2,453 \mathrm{~b}$ \\
$100 \%$ LUZ & $88,709 \mathrm{a}$ & $1,859 \mathrm{~b}$ \\
\hline MÉDIA & 86,081 & 2,651 \\
CV (\%) & 7,89 & 12,38 \\
\hline
\end{tabular}

Nota: Médias seguidas de mesma letra não diferem estatisticamente pelo teste de Tukey a 5\% de significância. 


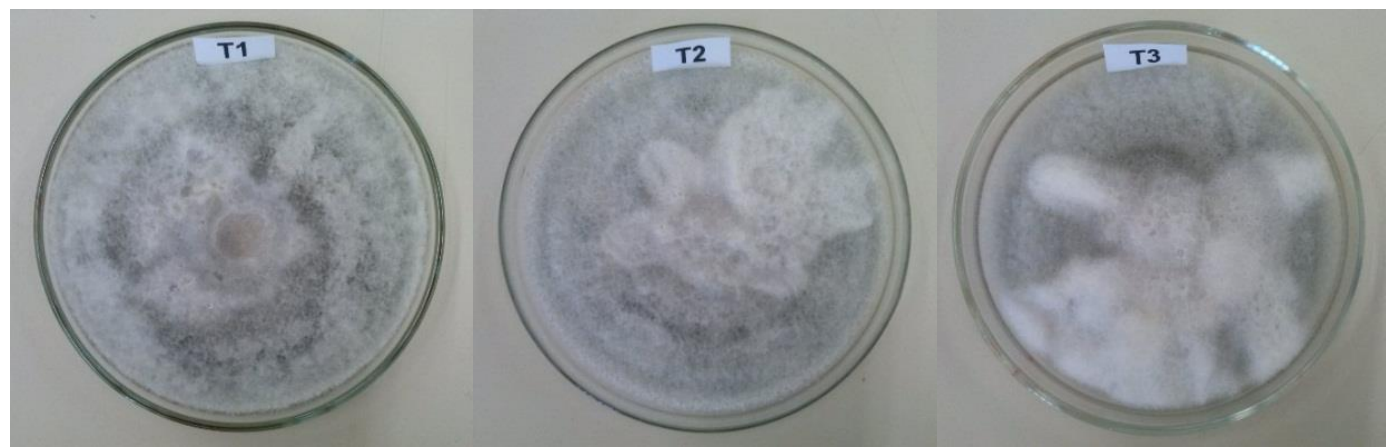

Figura 2. Detalhe de colônias de Alternaria solani submetidas à diferentes fotoperíodos, sendo T1 (0\% LUZ); T2 (50\% LUZ) e T3 (100\% LUZ).

Fonte: a autora, 2014.

Silva e Melo (1997), assim como no presente trabalho, ao avaliarem a taxa de crescimento micelial de Alternaria alternata sob diferentes regimes de luz, observaram que os fotoperíodos escuro, alternado e luz contínua não apresentaram diferença significativa. Entretanto, os mesmos também obtiveram maior esporulação no escuro.

Diferentemente dos resultados apresentados, Colturato (2006) avaliando fotoperíodo de 12 horas e escuro, verificou que as colônias fúngicas apresentaram igual crescimento até o quinto dia. Após dois dias, as placas armazenadas no escuro apresentaram pequena diferença no crescimento micelial, entretanto, não foi verificada a presença de esporos de Alternaria alternata.

A influência do fotoperíodo também foi observado por Ávila et al. (2000), constatando estes, assim como no presente trabalho, que o escuro contínuo é o regime de luz mais adequado para esporulação de Alternaria cassiae.

Rodrigues (2005) obteve maior esporulação de Alternaria solani quando alternou o regime entre luz e escuro (12 horas cada) com fotoperíodo de 24 horas não obtendo tendência bem definida de esporulação. Este também observou que nenhum isolado esporulou em escuro contínuo. Este fato é contraditório com o presente trabalho, podendo ser explicado pela diferença dos métodos de avaliação.

Os resultados obtidos foram diferentes quando comparados com Leão et al. (2012), ao avaliarem a influência dos meios de culturas sob diferentes regimes de luz na produção de esporos de Ascochyta cucumis, resultando em diferença entre os tratamentos, favorecendo o regime de luz contínua.

Resultados opostos também foram observados por Nozaki et al. (2004), na qual o regime de luminosidade claro contínuo foi mais favorável para o crescimento micelial e produção de pnídios de Diaporthe citri.

As diferenças encontradas nos diferentes estudos podem serem explicadas por se tratarem de patógenos com características morfológicas distintas.

\section{INFLUÊNCIA DA TEMPERATURA NO CRESCIMENTO MICELIAL E ESPORULAÇÃO DE Alternaria solani}

O crescimento micelial de Alternaria solani submetido a diferentes temperaturas concluiu o crescimento aos 7 dias após a inoculação, quando a colônia atingiu a borda da placa de Petri, podendo ser observado na Figura 3. 


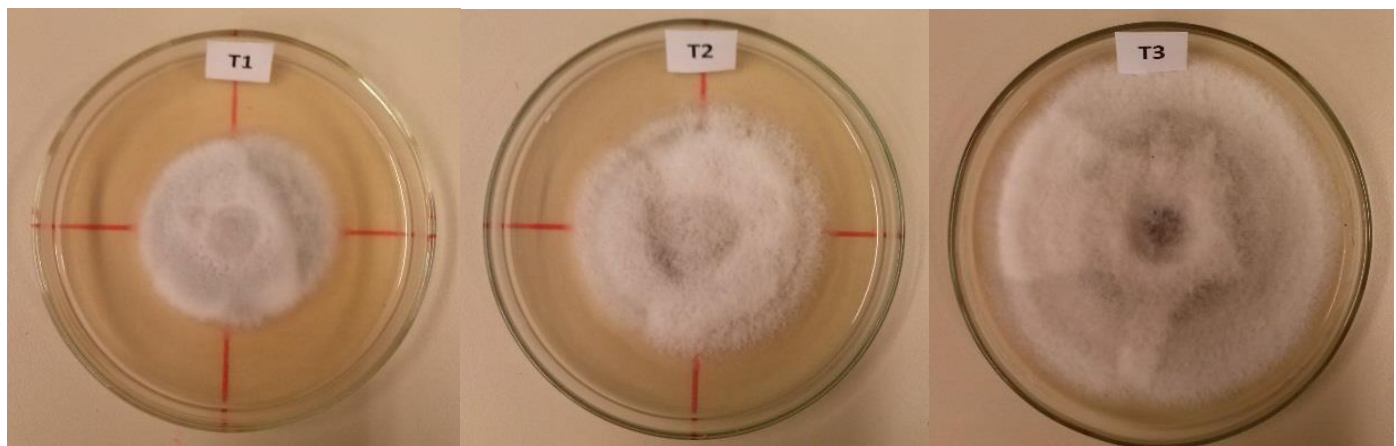

Figura 3. Detalhe da colônia de Alternaria solani submetidos a diferentes temperaturas, sendo $\mathrm{T} 1\left(20^{\circ} \mathrm{C}\right)$, $\mathrm{T} 2$ (temperatura ambiente) e $\mathrm{T} 3\left(30^{\circ} \mathrm{C}\right)$.

Fonte: a autora, 2014.

$\mathrm{Na}$ condição de temperatura em $30^{\circ} \mathrm{C}$ a colônia atingiu o crescimento micelial máximo em menor tempo, diferindo estatisticamente das demais. Quanto a esporulação, pode-se observar que a temperatura de $30{ }^{\circ} \mathrm{C}$ também diferiu-se estatisticamente das demais, apresentando-se mais favorável para a reprodução do patógeno (Tabela 3).

Tabela 3. Crescimento micelial $(\mathrm{mm})$ e esporulação $\left(\times 10^{4} / \mathrm{mL}\right)$ de Alternaria solani submetidos a diferentes temperaturas. Toledo, 2014.

\begin{tabular}{ccc}
\hline TEMPERATURA & CRESCIMENTO MICELIAL & ESPOROS \\
\hline $20{ }^{\circ} \mathrm{C}$ & $55,149 \mathrm{~b}$ & $0,281 \mathrm{~b}$ \\
AMBIENTE & $61,389 \mathrm{~b}$ & $0,218 \mathrm{~b}$ \\
$30{ }^{\circ} \mathrm{C}$ & $86,102 \mathrm{a}$ & $1,094 \mathrm{a}$ \\
\hline MÉDIA & 67,547 & 0,531 \\
$\mathrm{CV}(\%)$ & 9,47 & 21,82 \\
\hline
\end{tabular}

Nota: Médias seguidas de mesma letra não diferem estatisticamente pelo teste de Tukey a 5\% de significância.

Esses resultados podem ser comprovados pela temperatura ótima da proliferação do patógeno, uma vez que temperaturas aproximadas de $30{ }^{\circ} \mathrm{C}$ são as ideais para ocorrência de severas epidemias.

Resultados como estes também foram observados por Silva e Melo (1997), para Alternaria alternata. Segundo os autores, a esporulação foi favorecida pela ausência de luz à uma temperatura ambiente de $28^{\circ} \mathrm{C}$.

Colturato (2006) avaliou a produção de conídios de Alternaria alternata sob diferentes temperaturas, obtendo resultados semelhantes ao presente trabalho, na qual a temperatura de $28{ }^{\circ} \mathrm{C}$ apresentou-se como a melhor para obtenção de esporos. Entretanto, contrariamente, na temperatura de $25^{\circ} \mathrm{C}$ houve maior crescimento micelial do patógeno.
Temperaturas entre 20 e $25{ }^{\circ} \mathrm{C}$ foram constatadas por Nozaki et al. (2004), como as melhores para crescimento micelial de Diaporthe citri, diferindo-se do presente trabalho.

Pulz e Massola (2009) também obtiveram o melhor crescimento micelial em três meios de cultura, na temperatura de $25{ }^{\circ} \mathrm{C}$ para a colônia de Alternaria solani e $A$. dauci. Sendo que para o patógeno estudado, a temperatura de $30^{\circ} \mathrm{C} \mathrm{com}$ meio de cultura $\mathrm{V} 8$ foi o ponto máximo, após este o crescimento decaiu.

Pinheiro (2012) verificando as alterações de temperatura sob o patógeno Alternaria porri verificou que o maior crescimento micelial se deu com a temperatura de $25^{\circ} \mathrm{C}$, porém, a máxima esporulação foi encontrada no tratamento de $30{ }^{\circ} \mathrm{C}$, semelhante ao trabalho apresentado. 


\section{CONCLUSÃO}

1. O meio de cultura contendo BDA+Polpa de Tomate apresentou $\mathrm{O}$ melhor crescimento micelial e esporulação da Alternaria solani, apresentando-se como mais adequado para seu isolamento.

2. A luminosidade interferiu significativamente na esporulação do fungo, sendo o fotoperíodo

\section{REFERÊNCIAS}

ALFENAS, A.C.; MAFIA, R.G. Métodos em fitopatologia. Viçosa, 2007.

ÁVILA, Z.R. et al. Produção de inóculo de Alternaria cassiae. Pesquisa Agropecuária Brasileira, v. 35, n. 3, p. 533-541, mar. 2000.

CAMARGO, R.F. Tratamentos alternativos na qualidade sanitária e fisiológica de sementes de espécies florestais. 2007. 75 f. Dissertação (Mestrado em Agronomia) - Universidade Federal de Santa Maria, Santa Maria, 2007.

CANTERI, M. G. et al. SASM - Agri : Sistema para análise e separação de médias e experimentos agrícolas pelos métodos Scoft - Knott, Tukey e Duncan. Revista Brasileira de Agrocomputação, v. 1, n. 2, p. 18-24, 2001.

COLTURATO, A. B. Efeito do meio de cultura, temperatura, fotoperíodo e fungicidas no crescimento micelial e no controle de Alternaria alternata f. sp. citri, causador da mancha marrom do tugor murcote. 1981. 53f. Dissertação (Mestrado em Agronomia) Universidade Estadual Paulista, Botucatu, 2006.

DILL, A. M. Extratos vegetais no controle da pinta preta (Alternaria solani) em tomateiro. 2009. 55 f. Dissertação (Mestrado em Agronomia) - Universidade Federal de Santa Maria, Santa Maria, 2009.

FILGUEIRA, F.A.R. Solanáceas: agrotecnologia moderna na produção de tomate, batata, pimentão, pimenta, berinjela e jiló. Lavras: UFLA, 2003.

ISENBERG, M.; NOZAKI, M. H. Caracterização e controle alternativo de Diplocarpon rosae. Varia Scientia Agrárias, v. 3, n. 2, p. 135-145, 2009. escuro o que apresentou a maior esporulação. Não havendo diferença para crescimento micelial.

3. A temperatura de $30{ }^{\circ} \mathrm{C}$ foi o melhor tratamento para isolamento do patógeno, tanto em crescimento micelial, quanto em esporulação.

LEÃO, E.U. et al. Crescimento micelial e produção de conídios de Ascochyta cucumis em diferentes meios de cultura e regimes de luz. Bioescience Journal, Uberlândia, v. 28, n. 2, p. 325-331, marapr. 2012.

NOZAKI, M.H.; CAMARGO, M.; BARRETO, M. Caracterização de Diaporthe citri em diferentes meios de cultura, condições de temperatura e luminosidade. Fitopatologia Brasileira, v. 29, n. 4, p. 429-432, 2004.

PEREIRA, R.B.; CARVALHO, A.D.F.; PINHEIRO, J.B. Manejo da pinta preta: uma ameaça às lavouras de tomateiro a céu aberto. Brasília: Embrapa Hortaliças, 2013. (Comunicado técnico, 95).

PINHEIRO, G.S. et al. Crescimento e esporulação de Alternaria porri, sob diferentes temperaturas. Horticultura Brasileira, v. 30, n. 2, jul. 2012.

PULZ, P.; MASSOLA, J. R. Efeito de meios de cultura e fatores físicos no crescimento e esporulação de Alternaria dauci e A. solani. Summa Phytopathologica, Botucatu, v. 35, n. 2, p. 121-126, 2009.

QUEIROZ, F.M.; BATISTA, U.G.; BROMMNSCHENKEL, S.H. Avaliação de meios de cultura no crescimento micelial e esporulação de Alternaria brasiliensis. Fitopatologia Brasileira, v. 29, n. 5, set-out. 2004.

RODRIGUES, T.T.M.S. Produção in vitro de conídios infectivos de Alternaria solani. 2005. 41f. Dissertação (Mestrado) - Universidade Federal de Viçosa, Viçosa, 2005.

SILVA, C.M.M. S.; MELO, I.S. Caracterização de Alternaria alternata, degradador do fungicida carbendazim. Pesquisa Agropecuária Brasileira, Brasília, v. 32, n. 6, p. 621-626, jun. 1997. 
STANGARLIN, J.R. et al. Plantas medicinais e controle alternativo de fitopatógenos. Biotecnologia, Ciência e Desenvolvimento, n. 11, p. 16-21, 1999.

VALE, F.X.R.; ZAMBOLIM, L.; ZAMBOLIN, E.M. Manejo Integrado das doenças do tomateiro: epidemiologia e controle. In: ALVARENGA, M. A R. Tomate: produção em campo, em casa de vegetação e em hidroponia. Lavras: Editora UFLA, 2004.
Recebido para publicação em 29/06/2015

Revisado em 07/06/2017

Aceito em 16/06/2017 